\title{
Surveying the State of Higher Education in Energy Efficiency, in Australian Engineering Curriculum Cheryl J Desha $^{1}$, Karlson (Charlie) Hargroves ${ }^{2}$ \\ ${ }^{1}$ School of Engineering, Griffith University, Australia
}

${ }^{1}$ Education Director, The Natural Edge Project, hosted by Griffith University and Australian National University

${ }^{2}$ Research Fellow, Science, Environment, Engineering, and Technology Group, Griffith University, Australia

${ }^{2}$ Project Director, The Natural Edge Project, hosted by Griffith University and Australian National University

${ }^{2}$ Institute for Sustainability and Technology Policy, Curtin University, Perth, Australia.

* Corresponding author. Tel.: +61 73735 6635; Fax.: +61 73735 7459; E-mail addresses: c.desha@griffith.edu.au, and charlie@naturaledgeproject.net.

\section{Abstract}

This paper presents the method and results of a survey of 27 of the 33 Australian universities teaching engineering education in late 2007, undertaken by The Natural Edge Project (hosted by Griffith University and the Australian National University) and supported by the National Framework for Energy Efficiency. This survey aimed to ascertain the extent of energy efficiency (EE) education, and to identify preferred methods to assist in increasing the extent to which EE education is embedded in engineering curriculum. In this paper the context for the survey is supported by a summary of the key results from a variety of surveys undertaken over the last decade internationally. The paper concludes that EE education across universities and engineering disciplines in Australia is currently highly variable and ad hoc. Based on the results of the survey, this paper highlights a number of preferred options to support educators to embed sustainability within engineering programs, and future opportunities for monitoring EE, within the context of engineering education for sustainable development (EESD).

Keywords: State of Engineering Education for Sustainable Development; Energy Efficiency; National Survey; Australia.

\section{Introduction}

Engineers are increasingly being called upon to innovate in a range of new areas, including improving the energy efficiency (EE) of engineered systems, processes and products, along with developing and maintaining renewable and low greenhouse gas emissions energy generation technologies. The Intergovernmental Panel on Climate Change (IPCC) has been warning since 1988 that all nations need to stabilise their concentrations of carbon dioxide $\left(\mathrm{CO}_{2}\right)$ equivalent emissions, and that this will require significant global reductions in the order of 60 to 80 percent by 2050 [1]. However, the International Energy Agency (IEA) also forecasts that if policies remain similar to those currently in place, world energy demand is set to increase by over 50 percent between now and 2030 [2]. Although renewable and low-emission options are already available, energy demand must be reduced to facilitate a timely and cost effective transition. Clearly then, there is a need for commitment around the globe to both reduce greenhouse gas emissions from energy supplied and reduce energy demand [3,4]. Such a commitment would involve the development of tailored sophisticated responses involving every country and across all engineering and design disciplines, addressing significant variations in national policies, natural endowments, levels of development and per capita emissions. Given the complexity of such solutions, a common theme for all countries would be a concerted education and curriculum renewal effort, particularly 
as activities in this area have considerable lag times before graduates begin making key decisions in their field.

More than a decade ago, the United Nations Environment Program (UNEP), Word Federation of Engineering Organisations (WFEO), World Business Council for Sustainable Development (WBCSD), and the École des Ponts Paris Tech (ENPC) [5] supported a key international conference on engineering education and training for sustainable development. One of the key outcomes of this conference was a collective realisation that engineering education has a critical role to play in equipping graduates with the knowledge and skills necessary to create the capacity within the engineering profession, to deliver solutions and underpin the global economy's future.

The United Nations has defined education for sustainable development (ESD) as encouraging 'changes in behaviour that will create a more sustainable future in terms of environmental integrity, economic viability, and a just society for present and future generations' [6]. According to the World Federation of Engineering Organisations (WFEO), for engineering this means playing, 'an important role in planning and building projects that preserve natural resources, are cost-efficient and support human and natural environments' [7]. Hence, effectively undertaken engineering education for sustainable development (EESD) is a broad area covering technical, social and economic aspects.

Although there is increasing research on ways to improve engineering education for the $21^{\text {st }}$ Century, there has not yet been a detailed assessment of the global state of EESD [8]. In the absence of such information, this paper begins by discussing a number of surveys that have been used to assess the progress of higher education institutions (HEIs) in EESD. In particular, it summarises the results of key surveys over the last two decades on the extent to which EESD is embedded in curriculum. The paper then presents the findings of a recent major survey in Australia undertaken by the authors, which contributes to the body of survey literature to-date in the subtopic example of energy efficiency (EE) education, which includes energy demand (i.e. reducing energy consumption), and energy supply (i.e. changing to low-carbon options). The authors note that EE is not considered to be a potential proxy or replacement indicator for sustainability content, rather it is an example of a new area of practice that needs to be rapidly integrated into engineering courses, in addition to topics like water and materials efficiency. Indeed, such topics can be included as ESD subtopics or instruments, but ESD is more than their individual contributions. Further to the Australian survey findings on the sub-topic of EE, the authors outline a number of options for improving EE content and monitoring, synthesising experiences of researchers attempting other curriculum renewal initiatives and from the authors' own experiences.

\subsection{Global Context: a Lack of Information}

A 2003 report by the US National Council for Science and the Environment noted that baseline information about the status of sustainability education and practice in any nation is largely absent [9]. A detailed review of EESD literature by Desha and Hargroves [10] found that this situation has remained largely unchanged. Despite growing calls for EESD, the paper concluded there has not yet been a comprehensive assessment of the extent of sustainability content included in engineering education globally, or an assessment of whether critical sustainability literacies have been incorporated into engineering curriculum. Assessments of sustainability within universities still tend to be at the campus operations level, [11] focusing on the generation of policy statements and the implementation of environmental management systems, rather than at the curriculum level for a particular discipline. 
This lack of information is problematic in raising awareness about the need for curriculum renewal - where an early question is likely to be 'what is the extent of the problem and how do we know this?' - and in subsequently gaining funding and resources for curriculum renewal initiatives. The authors suggest three possible reasons for this lack of information gathering to-date, including:

1. Difficulty in assessing the extent to which sustainability knowledge and skills are embedded within the curriculum.

2. The time and resource intensive nature of conducting a global survey across the thousands of departments offering engineering degrees in many different languages.

3. Potential reluctance of professional organisations, accrediting bodies or the universities themselves to undertake the survey, due to possible planning, resourcing and accreditation implications of what might be found.

With these considerations, it is perhaps not surprising that there has not been a strong call from any one group for a comprehensive review, despite it being an important step in establishing what needs to be done to enable a global transition to EESD.

\section{An Overview of Key Surveys on the State of EESD}

Despite the lack of a comprehensive review of the state of EESD, a small number of surveys have been undertaken over the past decade that may be used as an indication of progress towards EESD, briefly highlighted in the following paragraphs.

In 1998, the World Engineering Partnership for Sustainable development (comprising WFEO, the International Federation of Consulting Engineers (FIDIC), and the International Union of Technical Associations (UATI)) circulated a questionnaire to national members of WFEO in an endeavour to provide an improved benchmark for engineering progress, concluding that, 'the survey does not indicate a strong or consistent approach to the environment and sustainable development in engineering education or that, on a country average, much more than 10 per cent of time in 10 per cent of courses is devoted to these aspects' [12].

Between 2000 and 2002, the University of Surrey (UK) and the University of Melbourne (Australia) collaborated to undertake a survey of a sample of international engineering students on their level of knowledge and understanding of sustainable development, which as far as its authors were aware, was the first of its type [13]. The researchers suggested from the findings of 21 respondents from 40 invitees that the level of sustainable development knowledge was not satisfactory, and that significant knowledge gaps existed within the curriculum [14].

In 2002, engineering educators at the Royal Melbourne Institute of Technology invited 21 Australian universities to participate in a survey in relation to the status of sustainability education in these institutions. Assessing responses received from approximately a quarter of these HEIs, the researchers concluded that, 'a handful of universities are engaged in this education for a wide range of their students, and in some universities more students of particular disciplines are gaining the exposure. However, there are clear barriers to the introduction and expansion of sustainability education' [15].

Following the 2004 Declaration of Barcelona, in 2006 Chalmers University of Technology, Delft Technical University, and the Technical University of Catalonia, produced a report called The Observatory which assessed the status of EESD in European Higher Education, in collaboration with the Alliance for Global Sustainability [16]. The report benchmarked a sample of 51 European Universities who participated in providing survey data, against examples and statements from 
outside Europe. The 2006 report concluded that, 'to date, there is no European University that shows sufficient progress in EESD to be considered an inspiration' [17].

In 2007, as part of the Forum for the Future's Engineers of the 21st Century Programme, two young engineers surveyed 499 young engineers (online) who had graduated 2 to 10 years ago with regard to sustainability literacy [18]. The surveyors suggested, based on the findings, that almost two thirds of past graduates had felt that sustainability was either important or very important to their job role today, however 40 percent of their university lecturers had inadequate knowledge of sustainability and only 30 percent had a positive to passionate attitude about the subject.

Between 2007 and 2008, the US Centre for Sustainable Engineering conducted a benchmarking survey on the extent of sustainable engineering education within 1,368 engineering departments (or the equivalent), with just over one fifth of the invited 364 American universities and colleges participating [19]. The researchers concluded that, 'the engineering education community is now at a critical juncture. To date, there has been a significant level of "grass-roots" activities but little structure or organization. The next step will be for engineering accreditation bodies to think critically about what should or should not be included in a curriculum into which sustainable engineering has been incorporated' [20].

In 2008, a second survey was undertaken by The Observatory initiative [21]. Of the 57 universities participating in the 2008 survey, most had not participated in the 2006 survey, making it difficult to directly compare the results of the successive reports. However, the data did indicate that a growing number of institutions from European countries are actively engaged in sustainability activities.

\section{2007 Australian Survey - Energy Efficiency Education}

In 2007, the Australian National Framework for Energy Efficiency (NFEE) provided funding for the authors (members of The Natural Edge Project, hosted by Griffith University and the Australian National University) to undertake a survey on the state of education for EE in Australian engineering programs. The following paragraphs summarise the rationale, methodology and results of the survey, for which a full report (including the questionnaires) is available online [22]. Through this summary, the authors hope to demonstrate how the findings from an investigation of a subtopic such as EE within the complex field of sustainability can be used to engage with academia on the broader topic of EESD, and how the information obtained through such a survey can be useful in addressing barriers to EESD.

\subsection{Survey Rationale}

With the ongoing monitoring in Europe mentioned above, the relatively small amount of data in key reports concerning Australian engineering education over the last 2 decades [23,24,25], and the increasing global dialogue about the importance of addressing energy demand and supply, the authors observed a need to investigate the extent of energy related education in Australia, in particular in energy generation, distribution and consumption.

\subsection{Survey Aims and Terminology}

The survey asked the question, 'What is the state of education for energy efficiency in Australian engineering education?' Its aims included validating literature review findings and experiences by the authors and peers, regarding EE curriculum gaps in Australian engineering education, and seeking feedback on preferred methods to embed knowledge and skills on EE into university engineering programs. 
In the survey, the term 'department' refers to the level where engineering programs are coordinated, and to which lecturers belong (also referred to by universities as a faculty, or school); 'program' refers to the award that a student works towards, and which is made up of a certain number of approved courses (also referred to by universities as a 'course', or 'degree'); and 'course' refers to a unit of work undertaken, which is part of the overall 'program' of study (i.e. a proportion of a nominal full study year, also referred to by universities as a 'unit' or 'subject').

\subsection{Survey Method}

The project team selected a paper-based questionnaire consisting of two components (with ethics approval by Griffith University). The first was a 16 page Lecturer Questionnaire, comprising 4 open-ended and 36 closed questions with a completion time of approximately 30 minutes. This questionnaire was issued in hard copy and electronic format to the heads of department of all 33 Australian universities providing engineering undergraduate and/or post-graduate programs. It included an invitation for completion by every lecturer teaching energy related material within engineering education. Lecturers receiving the questionnaire were also invited to forward it to colleagues responsible for course/s covering energy related material who may also be interested in participating. This invitation was followed up by one or more phone calls by the project team to provide support, clarification, and encouragement to complete the survey.

The second component was a 2 page Student Questionnaire, comprising 1 open-ended and 9 closed questions with a completion time of approximately 5 minutes. This was provided to all lecturers who received the Lecturer Questionnaire, to distribute and collect in one or more of their classes where energy related material was taught. Lecturers were reassured through email and follow-up correspondence that student responses were not a requirement for their participation in the survey, and that reporting would not identify the individual institution, course, lecturer, or student, ensuring student and faculty anonymity.

Results of the two questionnaires were cross-checked for additional context and validity of interpretation through semi-structured telephone interviews with a subset of Australian academics who were experienced in engineering education for EE (these participants had already indicated their availability for comment through involvement in the CSIRO textbook project).

\subsection{Survey Sample Characteristics}

The strong response rate of 82 percent for the lecturer questionnaires gave the authors confidence that the survey had reached a representative sample of the target audience. Through the invitation process, 59 lecturers registered their interest in the study (i.e. providing name and contact details to receive the questionnaire), as shown in Table 1. Forty-four lecturers from 27 of the 33 universities offering engineering programs completed and returned questionnaires for one or more of their courses, totalling 48 courses, including universities in every state and territory of Australia, spanning small to large engineering departments and programs. Such a high level of participation may have been due to several factors, including the topical nature of the survey having broad interest among engineering department faculty, personal contact with by the project team, and assurance of the anonymity of results.

Table 1. Lecturer Questionnaires - Summary of Participation 


\begin{tabular}{c|ccc|ccc}
\hline \multirow{2}{*}{ State } & \multicolumn{2}{|c|}{ University Participation Data } & \multicolumn{3}{c}{ Lecturer Participation Data } \\
\cline { 2 - 7 } & $\begin{array}{c}\text { Teaching } \\
\text { Engineering } \\
\text { Education }^{\text {a }}\end{array}$ & $\begin{array}{c}\text { Where } \\
\text { Lecturers } \\
\text { Expressed } \\
\text { Interest }\end{array}$ & $\begin{array}{c}\text { Where } \\
\text { Lecturer/s } \\
\text { Responded }\end{array}$ & $\begin{array}{c}\text { Number of } \\
\text { Lecturers who } \\
\text { Registered } \\
\text { Interest }\end{array}$ & $\begin{array}{c}\text { Number of } \\
\text { Lecturers } \\
\text { who } \\
\text { Responded }\end{array}$ & $\begin{array}{c}\text { Number of } \\
\text { Questionnaires } \\
\text { Submitted c, d }\end{array}$ \\
\hline ACT & 3 & 2 & 2 & 3 & 3 & 3 \\
NSW & 6 & 6 & 5 & 11 & 7 & 7 \\
NT & 1 & 1 & 1 & 1 & 1 & 1 \\
QLD & 6 & 6 & 6 & 15 & 13 & 15 \\
SA & 3 & 2 & 2 & 5 & 2 & 2 \\
TAS & 2 & 2 & 2 & 5 & 3 & 5 \\
VIC & 8 & 7 & 6 & 12 & 8 & 8 \\
WA & 4 & 3 & 3 & 7 & 4 & 7 \\
\hline Total & $\mathbf{3 3}$ & $\mathbf{2 9}$ & $\mathbf{2 7}$ & $\mathbf{5 9}$ & $\mathbf{4 1}$ & $\mathbf{4 8}$ \\
\% & - & $\mathbf{8 8}$ & $\mathbf{8 2 \%}$ & - & $\mathbf{7 0 \%}$ & - \\
\hline
\end{tabular}

${ }^{a}$ This list was drawn from the university membership of the Australian Council of Engineering Deans.

${ }^{b}$ Five other lecturers expressed interest in the survey, but did not teach a course that could be counted in the questionnaire.

${ }^{c}$ Several lecturers in QLD, Tasmania and WA completed a questionnaire for more than one of their courses.

${ }^{d}$ Several lecturers provided generalised responses in one questionnaire that covered several courses, due to their curriculum structure (problem-based learning) where it is difficult to represent the range of energy efficiency education by responding about a single course. These completed questionnaires were counted as 1 course.

Student questionnaire responses were obtained from 18 courses, comprising 260 students across 8 universities in states and territories, except the Northern Territory and the ACT, as shown in Table 2. The authors suggest that the response rate (i.e. 18 data sets obtained from the 48 courses for which a lecturer response was received) is suitable to provide an indicative measure of the perceptions of engineering undergraduate and postgraduate students with regard to EE education in Australia.

Table 2. Student Questionnaires - List of Course Topics

\begin{tabular}{clccc}
\hline \multirow{2}{*}{ State } & Course Topic/ Discipline Area & \multicolumn{2}{c}{ Student Enrolment } & Number of \\
\cline { 3 - 4 } & & Undergraduate & Postgraduate & Respondents \\
\hline NSW & Eng. Geology \& Concrete Materials & $\checkmark$ & - & 26 \\
NSW & Energy Systems & $\checkmark$ & $\checkmark$ & {$[3,26]^{\mathrm{a}} 29$} \\
QLD & Energy Conversion and Utilisation & $\checkmark$ & $\checkmark$ & {$[11,17] 28$} \\
QLD & Renewable Energy Systems & $\checkmark$ & $\checkmark$ & {$[8,8] 16$} \\
QLD & Power System Reliability \& Planning & - & - & 16 \\
QLD & Energy and the Environment & $\checkmark$ & - & 9 \\
QLD & Advanced Industrial Economics & $\checkmark$ & $1^{\text {b }}$
\end{tabular}




\begin{tabular}{clccc}
\hline State & Course Topicl Discipline Area & Student Enrolment & $\begin{array}{c}\text { Number of } \\
\text { Dnamandannt } \\
{[1,22] 23}\end{array}$ \\
\hline SA & Electric Energy Systems & $\checkmark$ & $\checkmark$ & 17 \\
TAS & Thermal Engineering & $\checkmark$ & - & 23 \\
VIC & Architectural Engineering & $\checkmark$ & - & 5 \\
VIC & Civil Engineering & $\checkmark$ & - & 34 \\
VIC & Civil Engineering & $\checkmark$ & - & 30 \\
WA & Engineering Sustainable & $\checkmark$ & - & 3 \\
& Development & & $\checkmark$ & 260 \\
\hline
\end{tabular}

Total Student Responses

${ }^{a}$ The split between undergraduate and postgraduate student numbers is shown in square brackets

${ }^{b}$ This questionnaire was given to 1 student to represent the class of approximately 20 students

Student response data is summarised in Table 3 below, where two thirds (67 percent) of undergraduate respondents were in their final two years of undergraduate studies (i.e. 3rd or 4th year). Most postgraduate responses were from students in their first 2 years of study.

Table 3. Student Questionnaires - Student Response Data

\begin{tabular}{lccccccc}
\hline Level: & Year 1 & Year 2 & Year 3 & Year 4 & Other & Sub-Total & $\%$ \\
Undergraduate (No.) & 13 & 58 & 94 & 48 & 6 & $\mathbf{2 1 9}$ & $\mathbf{8 4 \%}$ \\
Undergraduate (\%) & $6 \%$ & $26 \%$ & $43 \%$ & $22 \%$ & $3 \%$ & - & - \\
Postgraduate (No.) & 34 & 6 & 0 & 1 & 0 & $\mathbf{4 1}$ & $\mathbf{1 6 \%}$ \\
Postgraduate (\%) & $83 \%$ & $15 \%$ & $0 \%$ & $2 \%$ & $0 \%$ & - & - \\
\hline & & \multicolumn{7}{c}{ Data Set Total: } & $\mathbf{2 6 0}$ & $\mathbf{1 0 0 \%}$ \\
\hline
\end{tabular}

While this survey does not claim to cover every course teaching energy related material to engineers in Australia, or to represent the views of every lecturer teaching such content or the views of their universities, the authors are confident that the findings adequately represent the general composition of such courses and lecturer perspectives in Australia. The analysis did not include in-depth statistical computations, due to the indicative (rather than comprehensive) and qualitative nature of the study. Hence, descriptive terms such as 'more than half' and 'approximately' are used to summarise the findings. Actual percentages for all responses are available from the full report online.

\subsection{Survey Key Findings}

It was concluded from the survey findings that the state of education for EE in Australian engineering education is currently highly variable and ad hoc across universities and engineering disciplines, as highlighted by the following key findings:

\section{1) Location of Content in Engineering Programs}

The survey results suggest that EE education is not embedded across all engineering disciplines and that there is confusion over where and what EE knowledge and skills should be taught. In particular: 
- Nearly two thirds (65 percent) of the lecturers surveyed thought that students enrolling in their course expected to learn about energy efficiency issues and solutions, however, students across all disciplines do not appear to be clear on where in their degree program, or how much, EE content should be taught.

- Mechanical and electrical engineering students appear more likely to be taught EE content, followed by environmental, civil, and chemical engineering students.

- EE education in any course appears to be driven by the individual interests and research pursuits of the lecturers involved rather than formal strategic integration.

EE appears to be mostly taught as part of a broader content area to second and third year undergraduate students, with more targeted EE topics in fourth year undergraduate, and postgraduate studies. For more than half of the surveyed courses (55 percent), lecturers reported that their course could include more (in-depth) EE content, with one respondent noting, “... I would still very much like to see more resources developed for Energy Efficiency. In particular information in the local context (i.e. Australian) is very patchy or increasingly dated. There are numerous reports from Europe, USA (especially California) and elsewhere on energy efficiency, however, Australian data is less common ...”. Most respondents (74 percent) thought that the increase in content should be in the area of 'Applying energy efficiency theory and knowledge' and more than half (52 percent) thought their course could include more on 'Knowledge/ Information about Energy Efficiency'.

\section{2) Level of Integration of Topical Issues in Energy Efficiency}

The level of integration of topical EE issues into courses appears to be very low. Nearly half (44 percent) of the lecturers surveyed did not think that their course taught 'general design theory' associated with energy efficiency, for example including concepts such as embedded energy, cradle to cradle philosophy, resource productivity, life cycle assessment, and demand side management. More than a quarter (29 percent) of lecturers considered energy efficiency to be only a minor component of the course (i.e. comprising less than 5 percent of the curriculum).

Even mainstream contextual topics such as 'carbon dioxide and other greenhouse gas emissions from energy generation' and 'the link between greenhouse gas emissions and global temperature change' were only covered in detail by up to a third of those courses surveyed (33 and 23 percent respectively), and mentioned by less than half (38 and 42 percent respectively). The survey suggests that students across undergraduate and postgraduate levels think they understand the terms 'sustainable development' and 'energy efficiency' very well, and their responses suggest that they are making some connection to issues in the media. However, students appear to have a low to moderate appreciation of how 'energy efficiency' might be directly related to their future careers.

Two areas of content that were highlighted by the lecturers' survey as being taught in detail and highlighted in the student surveys as being understood well include 'Efficiency, resource efficiency and energy efficiency' and 'Energy generation and transmission losses'. However, despite the students' perception of how well they understood the term 'energy efficiency' and the extent of such education, the data suggests that most did not have an in-depth understanding of the particular principles and theory investigated in the survey questions.

\section{3) Level of Student Exposure to Energy Efficiency Content}

Together with results regarding content coverage, the survey indicated a substantial shortfall in the inclusion of EE theory, knowledge, application and assessment in Australian engineering 
education. While lecturers appear to be engaging with EE knowledge/information, there appears to be a low level of student exposure to theory. In particular, the extent to which EE concepts and principles are included in courses appears to be low to very low. The three areas of content highlighted by the survey as not being taught in detail and not understood by students include: 'Product Stewardship and Responsibility', 'Decoupling energy utility profits from kilowatt-hours sold' and 'Incremental Efficiency versus Whole System Design'.

Student exposure to applying EE principles and theory and information/knowledge to worked examples appears to be low to moderate with many courses that include some EE content in their courses not including related reading resources for students. Quite a number of courses do not use case studies and if used, they do not tend to go beyond the traditional sectors of industry and energy utilities as indicated in Table 4.

Table 4. Percentage of surveyed courses with case studies on particular topics

\begin{tabular}{lc}
\hline Type of Energy Efficiency Case Studies Included - By Sector & Percentage of Courses \\
Opportunities in the industry sector & $\mathbf{5 5 \%}$ \\
Gains in the energy utilities sector & $\mathbf{4 5 \%}$ \\
Gains in the transportation sector & $\mathbf{3 4 \%}$ \\
Gains in the built environment sector & $\mathbf{3 1 \%}$ \\
\hline Type of Energy Efficiency Case Studies Included - By Technology & Percentage of Courses \\
Opportunities in motor systems & $\mathbf{3 1 \%}$ \\
Energy efficiency gains in boilers & $\mathbf{3 1 \%}$ \\
Energy efficiency gains in HVAC systems & $\mathbf{2 7 \%}$ \\
Energy efficiency gains in lighting & $\mathbf{2 7 \%}$ \\
Energy efficiency gains in appliances and equipment & $\mathbf{2 5 \%}$ \\
\hline
\end{tabular}

\section{4) Perceived Barriers to Curriculum Renewal}

The survey identified two particular barriers to curriculum renewal for EE education. Nearly two thirds (58 percent) of the lecturers surveyed considered 'The potential for course content overload' to be a challenge for curriculum renewal to integrate more EE knowledge and skills and more than half considered 'Having insufficient time to prepare new materials' (i.e. not enough time to modify course notes, lectures, course outlines, assessment etc) to be a challenge. In contrast, less than a quarter (23 percent) of lecturers surveyed considered 'Insufficient resources to include the materials (i.e. not enough funding to spend time or employ someone to renew the course)' to be a challenge, and only 13 percent considered 'Lack of support regarding curriculum renewal by University/ colleagues' to be a barrier, with one respondent noting, "Some Faculty staff may resist but most see need". Additional comments provided by respondents indicates that some lecturers do not appear to be aware of content that is beyond 'introductory', with one respondent noting, "One issue with this material is possibly low technical content; the 'fit' in highly technical subjects can be difficult when discussing some more general concepts". Respondents' comments also indicate that EE content is perceived as adding to the course content, rather than being a way to refine or consolidate existing course content.

5) Preferred Options for Improving the Extent of Energy Efficiency in Engineering Education 
Of those courses where lecturers said more could be done, Table 5 summarises the responses with regards to which resources could assist in including EE Education. Lecturers were keen to receive assistance through accessing case studies on EE examples in engineering (i.e. worked reallife examples that show how the theory and knowledge is applied), accessing lists of good quality material (for example audio-visual materials, text books and other references), and accessing customised sets of readings for engineers generally. Lecturers surveyed did not appear keen to receive professional development (i.e. additional training) on EE, perhaps due to already demanding work loads.

Table 5. Summary of responses with regard to which resources can assist EE education

$\begin{array}{lr}\text { Resources that could be used to assist EE education } & \text { Percentage } \\ \text { Agreement }\end{array}$

A set of case studies on energy efficiency examples in engineering $77 \%$

List of related documentaries/TV episodes etc. and their sources $55 \%$

A list of key energy efficiency textbooks and references for engineers $55 \%$

A customised set of readings on energy efficiency for engineers generally $48 \%$

Lecture notes on key energy efficiency issues and solutions for engineers $45 \%$

A set of mini-lectures (i.e. lecture guides and study materials) on various energy efficiency topics

Special guest/ expert lectures on energy efficiency

$42 \%$

Lecture notes on energy efficiency opportunities, specifically by technology

A customised set of readings on energy efficiency, relevant to engineering discipline/s

Almost all of the lecturers (90 percent) wanting assistance with accessing content about EE preferred the resources to be available through open access, online learning modules. This is in stark contrast to restricted access sources (6 percent), or intensive short courses undertaken in person (13 percent) or remotely (10 percent).

Some lecturers indicated preference for third party endorsement of materials, but comments indicated that the reason and messaging of the endorsement needs to be clear. Nearly half of those surveyed (45 percent) thought that endorsement by a third party would increase the likelihood of the use of content developed on energy efficiency. Of these, the majority (81 percent) thought that endorsement by the Institution of Engineers Australia would increase the likelihood that the material is used, and nearly half (44 percent) thought that third party endorsement by the Australian Federal Government would assist. Nearly a third (31 percent) thought that endorsement by other respected Australian universities would increase the likelihood that the material is used.

\subsection{Relevance of the Survey Findings}

These survey findings contribute to a growing global understanding of the current state of education in this sustainability topic. This could be further improved by repeating the survey at intervals of, for example, 3-5 years, in Australia and elsewhere, and comparing the results. Such ongoing monitoring and evaluation would provide valuable information as to the state of EE 
education, which could in turn inform realistic and targeted, measurable and time-bound objectives to support curriculum renewal in this regard. Based on such a standardised evaluation mechanism, additional surveys could also be undertaken in other areas of engineering education, such as water efficiency, renewable energy, and materials efficiency. A shorter EE survey could also be undertaken among a purposive sample of internationally renowned lecturers in engineering education for EE, to ascertain the extent of international leadership in this area. Results could be used as a resource to inform national capacity building policies, potential training opportunities in EE education, and program accreditation review.

These survey findings are also immediately relevant for senior management in engineering departments, Australian professional organisations, and government departments considering future programs and funding allocations, as they provide an indication of the preferred options for increasing EE education. Reflecting on the survey findings, the authors propose that there are a number of options for improving the extent of energy efficiency education within the engineering curriculum, including:

- Using the results of this survey, engineering departments could audit their degree programs (for example through a sustainability audit [26]), to identify the most effective way to allocate resources for embedding EE content within the curriculum.

- Content development could be funded to assist lecturers with incorporating two emerging important energy related areas of 'decoupling energy utility profits from kilowatt-hours sold' and 'product stewardship and responsibility', for which the survey found a lack of existing content.

- Case study development could be funded to create realistic and well-formulated EE learning tools that lecturers can easily access and incorporate.

- Awareness raising could be undertaken with regard to the availability of existing EE content. This includes for example, the authors' freely available and online publication funded by the CSIRO Energy Transformed: Sustainable Energy Solutions for Climate Change Mitigation [27], which was informed by this survey.

- The authors are also developing a free and publically available strategic 'turnkey' (i.e. selfevident) document, funded by the National Framework for Energy Efficiency, to assist the curriculum renewal process for EE education, drawing on behaviour change tools developed by McKenzie-Mohr [28].

\section{Concluding Comments}

Despite the growing calls for sustainability to be better integrated into engineering education for over two decades, and anecdotal information from students, teachers and future employers, there is a lack of data on the extent to which sustainability related knowledge and skills are present or absent in curriculum. This is problematic in raising awareness about the issue, and in gaining funding and resources for curriculum renewal initiatives. Despite a variety of existing challenges to obtaining such information, a number of smaller surveys have been undertaken over the last decade, which suggest a lack of sustainability knowledge and skills in engineering curriculum, and highlight leverage points to accelerate such education.

In the absence of a major international survey initiative on the state of EESD, the authors have proposed that there is the opportunity for researchers around the world to use sub-components of sustainability education - such as energy education - to obtain an indication about the extent to which sustainability is embedded within engineering education in their country. For example, EE is 
a very relevant issue in Australia and internationally, with relatively clear topic areas that can be monitored for inclusion in engineering curriculum.

The survey results highlight the need for access to content that covers EE theory, knowledge/information and application, catering for all engineering disciplines. The survey also highlights lecturer preferences for good content, practical and industry-relevant material, and access to problem based learning tools such as realistic and well-developed case studies on EE.

The authors hope that the survey methodology described in this paper will be of immediate use to researchers in other countries trying to assess the extent to which engineering curriculum embeds EE knowledge and skills, and to identify options for improvements. The authors also hope that the findings and considerations for moving forward may be of use to professional associations, accrediting bodies and departments around the world who are considering how to proceed with curriculum renewal in EE and other sustainability-related topic areas.

\section{Acknowledgements}

The authors are members of The Natural Edge Project (TNEP), which is a not-for-profit partnership for research and education on sustainable development. Formerly hosted by Engineers Australia (2002-2006), the project is now hosted by Griffith University and the Australian National University (www.naturaledgeproject.net). TNEP's mission is to contribute to and succinctly communicate leading research, case studies, tools and strategies for achieving sustainable prosperity across government, business and civil society, receiving mentoring and support from a wide range of experts and leading organisations internationally, through a generational exchange model.

The following colleagues are thanked for their valuable time in mentoring, review and providing contributions to this paper (in alphabetical order): Professor Adisa Azapagic, University of Manchester, United Kingdom; Mr Roy Chamberlain, Commonwealth Science and Industry Research Organisation (CSIRO), Australia; Professor Cliff Davidson, Carnegie Mellon University, America; Professor Neil Dempster, Griffith University, Australia; Dr Didac Ferrer Balas, Universitat Politècnica de Catalunya, Spain; Professor John Fien, Royal Melbourne Institute of Technology, Australia; Alex van Kuilenburg and Steven Liebregts (masters students), University of Applied Sciences, Hasdenbosch, Netherlands; Ms Val Macgregor, National Framework for Energy Efficiency, Australia; Dr Bill Metcalf, Griffith University, Australia; Professor Alan Pears, Royal Melbourne Institute of Technology, Australia; Professor David Thiel, Griffith University, Australia; Professor Ian Thomas, Royal Melbourne Institute of Technology, Australia; Survey participants (60 lecturers and 241 students); and Workshop participants on 'Accelerating Curriculum Renewal - Behaviours, Barriers and Benefits' at the 2008 EESD Conference 'Bridging the Gap’ (Graz, Austria).

\section{References}

[1] International Panel on Climate Change. Fourth Assessment Report WG2: Climate Change 2007: Impacts, Adaptation \& Vulnerability. International Panel on Climate Change, 2007.

[2] International Energy Agency. World Energy Outlook 2005. Press Release. IEA, 2005. Available at: http://www.iea.org/Textbase/press/pressdetail.asp?PRESS_REL_ID=163 (accessed 29 May 2009). 
[3] Lovins H, Hargroves K, Smith M, Juniper C. Prospering in a Carbon Constrained World: Profitable Opportunities for Greenhouse Gas Emissions Reduction, CCX/EUX Opportunities Report, 2005.

[4] Hargroves K. Smith M. Chapter 17: Profitable Greenhouse Solutions. The Natural Advantage of Nations: Business Opportunities, Innovation and Governance in the 21st Century, Earthscan/James and James Publishing, London, 2005:326.

[5] UNEP, WFEO, WBCSD, ENPC. Engineering Education and Training for Sustainable Development. Report of the joint UNEP, WFEO, WBCSD, ENPC Conference. Paris, France, 24-26 September 1997.

[6] UN General Assembly. Proclamation of the Decade of Education of Sustainable Development (2005 - 2014). 57th Session, UN General Assembly, 2002.

[7] WFEO. Engineers and Sustainable Development. World Federation of Engineering Organisations’ Committee on Technology, August 2002.

[8] Desha C, Hargroves K, Smith M. Addressing the Time Lag Dilemma in Curriculum Renewal towards Engineering Education for Sustainable Development. International Journal of Sustainability in Higher Education, 2009;10(2).

[9] Blockstein D, Greene J, editors. Recommendations for Education for a Sustainable and Secure Future. Washington DC: National Council for Science and the Environment, 2003.

[10] Desha C, Hargroves K, Smith M. Addressing the Time Lag Dilemma in Curriculum Renewal towards Engineering Education for Sustainable Development. International Journal of Sustainability in Higher Education, 2009;10.

[11] Lozano R. A Tool for a Graphical Assessment of Sustainability in Universities (GASU). Journal of Cleaner Production 2006;14(9-11):963-972.

[12] UNEP, WFEO, WBCSD, ENPC. Engineering Education and Training for Sustainable Development. Report of the joint UNEP, WFEO, WBCSD, ENPC Conference. Paris, France, 24-26 September 1997: Chapter 10: Appendices - IV WFEO Survey, p42.

[13] Azapagic A, Perdan S, Shallcross D. How much do engineering students know about sustainable development? The findings of an international survey and possible implications for the engineering curriculum. European Journal of engineering Education 2005;30(1):1-19.

[14] Ibid. p1.

[15] Thomas I, Nicita J. Sustainability Education in Australian Universities. Environmental Education Research 2002;8(4):475-492.

[16] The Alliance for Global Sustainability. The Observatory: Status of Engineering Education for Sustainable Development in European Higher Education, 2006, Technical University of Catalonia, Spain: EESD-Observatory. Available at: www.upc.edu./eesd-observatory/ (accessed 17 July 2008).

[17] Ibid, p3.

[18] Meddings L, Thorne T. Engineers of 21st Century: Engineering Education Project: What I Wish I'd Learnt at University. Report to the Forum for the Future's Engineers of the 21st Century programme. Australia: ARUP, 2008. 
[19] Allen D, Allenby B, Bridges M, Crittenden J, Davidson C, Hendrickson C, Matthews C, Murphy C, Pijawka D. Benchmarking Sustainability Engineering Education: Final Report. EPA Grant X3-83235101-0, 2008, Centre for Sustainable Engineering, Pittsburgh, America. Available at: http://www.csengin.org/benchmark.htm (accessed 12 March 2009).

[20] Ibid, p3.

[21] The Alliance for Global Sustainability. The Observatory: Status of Engineering Education for Sustainable Development in European Higher Education, Technical University of Catalonia, Spain: EESD-Observatory, 2008.

[22] Desha C, Hargroves K, Smith M, Stasinopoulos P, Stephens R, Hargroves S. State of Education for Energy Efficiency in Australian Engineering Education - Summary of Questionnaire Results. Australia: The Natural Edge Project (TNEP), 2007. Available at: http://www.naturaledgeproject.net/Documents/Energy_Efficiency_Survey_-_Summary.doc (accessed 27 July 2008).

[23] Engineers Australia. Changing the Culture: Review of Engineering Education. Australia: ATSE/ IEAust/ ACED/ DEETYA, 1996.

[24] ATSE. Government Submission on Education and Sustainable Development, Australian Academy of Technical Societies and Engineering, Report prepared by a Sub-Committee set up jointly by the ATSE Committee on Sustainable Development and the Committee on Education for Technological Sciences and Engineering. Victoria, Australia: ATSE, 1997. Available at: http://www.atse.org.au/index.php?sectionid=585 (accessed 25 July 2008).

[25] King R. Addressing the Supply and Quality of Engineering Graduates for the New Century. Sydney, Australia: The Carrick Institute for Learning and Teaching in Higher Education Ltd, 2008.

[26] Desha C, Hargroves K. Education for Sustainable Development Curriculum Audit (E4SD Audit): a curriculum diagnostic tool for quantifying requirements to embed sustainable development into higher education - demonstrated through a focus on engineering education. World Transactions on Engineering and Technology Education 2007;6(2).

[27] Smith M, Hargroves K, Stasinopoulos P, Stephens R, Desha C, and Hargroves S. Energy Transformed: Sustainable Energy Solutions for Climate Change Mitigation. Australia: The Natural Edge Project (TNEP), 2007.

[28] McKenzie-Mohr D, Smith W. Fostering Sustainable Behavior: An Introduction to Community-Based Social Marketing (Education for Sustainability Series). Washington: Academy for Educational Development (co-publishers) and Gabriola Island, Canada: New Society Publishers (co-publishers), 1999. 